\title{
A study on the perception of the stigma related to drug use in a sample of Italians and Belgians
}

\author{
Giuseppe Antonio Sciol ${ }^{11}$, José A. Carmona-Torres ${ }^{2 *}$, Alex Paniccia ${ }^{1}$, Andrea Battista ${ }^{1}$, Ilaria \\ Cavicchia $^{1}$ and Rachel M. Bishar \\ ${ }^{1}$ Department for the Treatment and Prevention of Drug Abuse, Isernia (Italy) \\ ${ }^{2}$ University of Almeria (Spain)
}

(Received May 8, 2014; Accepted December 14, 2014)

\begin{abstract}
The goal of the present study has been to exploratorily analyse the possible differences in perceived stigma on drug use between a sample of students and health services workers from Italy and Belgium. The Perceived Stigma of Addiction Scale (PSAS) (Luoma, Hair, Kohlenberg, Hayes, and Fletcher, 2010) was used. A total of 277 participants took part in this study. Outcomes showed that the perceived stigma among Italians was signifi- cantly higher (M $=23.68)$ than that reported by Belgians $(M=20.26)$. Authors argued that many factors (e.g., social, cultural, etc.) may explain the differences obtained. On the other hand, the existence of a stigma circuit (Scioli and Paniccia), which would share some similarities with the anxiety circuit, seems to trap the person in a vicious cycle of events that would make the relapse from addiction harder. The limitations and scope of the obtained results in the frame of this ex- ploratory study is discussed.
\end{abstract}

Keywords: drug abuse, stigma circuit, transcultural comparison, perceived stigma.

Un estudio sobre la percepción del estigma asociado al consumo de drogas en una muestra de italianos y no italianos

RESUMEN: El objetivo del presente estudio ha sido analizar de manera exploratoria las posibles diferencias en el estigma percibido asociado al consumo de drogas entre una muestra de estudiantes y trabajadores de los servicios de salud procedentes de Italia y Bélgica. Para este propósito, se utilizó el Perceived Stigma of Addiction Scale (PSAS) (Luoma, Hair, Kohlenberg, Hayes, y Fletcher, 2010). Un total de 277 participantes tomaron parte en este estudio. Los resultados mostraron que el estigma percibido entre los italianos fue significativamente mayor $(M=23.68)$ que el informado por la muestra de Bélgica $(\mathrm{M}=20.26)$. Los autores argumentan que varios factores (e.g., sociales, culturales, etc.) explicarían las diferencias obtenidas. Por otro lado, la existencia de un circuito del estigma (Scioli y Paniccia), el cual compartiría ciertas similitudes con el circuito de la ansiedad, parece atrapar a la persona en un círculo vicioso de eventos que haría más difícil la recuperación de la adicción. Se discuten las limitaciones y el alcance de los resultados obtenidos en el marco del presente estudio exploratorio. Palabras clave: abuso de drogas, circuito del estigma, comparación transcultural, estigma percibido. 


\section{INTRODUCTION}

Compulsive behavioral activities have become more apparent in our daily lives. Whether the behavior involves complicated food relationships, extreme exercise levels, or the extensive use of hand-held technologies such as smartphones in order to participate in social networks, excessive activity can reach a level of being considered an addiction. Metzer (1994) positioned that addiction, compulsion and attachments are a normal and inevitable part of human experience. Using this approach, it could be a mistake to consider addictive behaviors as unique from compulsive behaviors; addiction would be considered normative and even inevitable in our lives. Addiction could be recognized as just an amplified form of natural behavior with pathological lines.

In recent years the interest and concern about stigmatising attitudes towards people with mental disorders have increased. It is surprising that the stigma related to mental disorders not only remained throughout the years but has grown in the last decades (Farina, 1998; Phelan, Link, Stueve and Pescosolido, 2000). In this context, people with drug use disorders seem to be an especially vulnerable group. In particular, several studies have shown that people with drug use disorders are severely stigmatized compared to other groups of people with mental disorders (Rao et al., 2009; Schomerus et al., 2011). It is difficult to reduce this problem since stigmatizing attitudes regarding drug abuse are widely accepted, culturally endorsed and enshrined in law enforcement (Livingstone, Milne, Fang, and Amari, 2011).Thus, people with drug abuse problems can encounter several obstacles that could make their recovery more difficult. The normalisation of their lives is prevented not only because of the consequences of their problematic drug use but also because of the discriminatory and stigmatizing social reaction that comes from the people in their environment (Corrigan, 2000).

Stigma may be understood in terms of the different ways it manifests at the self, social and structural -institutional- levels (Corrigan, Kerr, and Knudsen, 2005; Rüsch, Angermeyer, and Corrigan, 2005). In particular, as occurs with other mental disorders, substance abusers in recovery could face stigma in various forms including enacted, perceived, and self-stigma (Link, Cullen, Streuning, Shrout, and Dohrenwend, 1989; Link, Yang, Phelan, and Collins, 2004). Enacted stigma refers to directly experienced social discrimination such as difficulties in obtaining an employment and experiencing interpersonal rejection. Perceived stigma refers to beliefs that members of a stigmatized group have about the prevalence of stigmatising attitudes in society towards them. Self-stigma refers to negative thoughts and feelings that emerge from identification with a stigmatised group and the consequences derived from that (Luoma et al. 2007).). The effects of these forms of stigmatising attitudes towards people with drug use problems can have an extensive influence resulting in risky behaviour (Simmonds and Coomber, 2009), poor physical and mental health (Ahern, Stuber, and Galea, 2007), not entering treatment (Cunningham, Sobell, Sobell, Agrawal, and Toneatto, 1993), delayed recovery (Buchanan and Young, 2000), non-completion 
of treatment (Brener, von Hippel, von Hippel, Resnick, and Treloar 2010), and social alienation. Stigma has the potential to affect all domains of their lives adversely including important social areas such as unemployment, housing and social relationships (Room, 2005; Livingstone et al. 2011).

The authors have experience working in rehabilitation centres located in rural Italy where small remote villages are commonplace. In this context it has been observed that a substantial number of drug addicts, after completing rehabilitation, chose not to return to their native towns in an effort to maintain their rehabilitated state. Those returning to live in their native towns usually relapsed back into addiction. Noticeably, studies comparing the possible differences in perceived stigma among different countries have not been found. This study is an effort to understand the levels of stigma those returning to their native environments after completion of rehabilitation may face. Concurrently, with the aim of considering cross-cultural implications of stigma, in the present exploratory study the possible differences in perceived stigma between a sample of Italian and Belgian people will be analysed.

\section{METHOD}

\section{Sample}

The sample consisted of 277 students and health workers from Italy $(n=200)$ and Belgium $(n=77)$. It is important to note that most of the participants preferred not to disclose information about their sociodemographic characteristics, including age and gender. Having this limitation and due to the exploratory nature of the present study, it was decided not to include the incomplete demographic data of the sample in this study.

\section{Measures}

The Perceived Stigma of Substance Abuse Scale (PSAS) (Luoma, Kohlenberg, Hayes, and Fletcher, 2010) was used. The PSAS consists of an 8 item selfreport scale which measures the level of stigma perceived towards drug users. All items are scored on a Likert scale with four options ranging from "totally disagree" to "totally agree", out of which six are reverse scored. The scale total score ranges from 8 to 32 , a higher score indicating greater perceived stigma.

\section{Procedure}

A non-probabilistic convenience sampling was used to recruit participants in person and through social media. The criterion for their inclusion was the ease for the researchers to recruit them from university and health services contexts. Those who fulfilled research criteria and who accepted to take part in this study received the questionnaire and sent it back filled in by mail. Despite their interest 
in participating in this study, most of the participants were reluctant to provide their personal details.

\section{RESULTS}

In order to analyse the possible differences in perceived stigma between the two samples, a comparison of averages using $t$-tests was performed. At the same time, Levene's $F$ test was used to assess the equality of variances.

A $t$-test was performed to compare the means referred to the perceived stigma on drug users between the Italian and Belgian samples. Based on the outcomes obtained by using the PSAS, the mean for the Italian sample was of 23.68 ( $S D=$ $2.49)$ while the Belgian scored $20.24(S D=3.26)$. An independent-sample $t$-test indicated that means in perceived stigma were significantly higher for Italians $(M=23.68, S D=2.49)$ than for Belgians $(M=20.24, S D=3.26), t(111)=9.42$, $p<0.01)$. Levene's test indicated unequal variances $(F=7.33, p<0.05)$, thus degrees of freedom were adjusted from 275 to 111 (see table 1).

Table 1. T Test for Independent Samples for Perceived Stigma on Drug Users

\begin{tabular}{lllllllll}
\hline & & \multicolumn{2}{c}{$\begin{array}{c}\text { Levene's test } \\
\text { for equality of } \\
\text { variances }\end{array}$} & & & & & t-test for equality of means \\
\cline { 2 - 9 } & $F$ & $p$ & $t$ & $d f$ & $p$ & $\begin{array}{c}\text { Mean } \\
\text { difference }\end{array}$ & $\begin{array}{c}\text { Std. error } \\
\text { difference }\end{array}$ \\
\hline $\begin{array}{l}\text { Perceived } \\
\text { stigma }\end{array}$ & $\begin{array}{l}\text { Equal variances } \\
\text { assumed } \\
\text { Equal variances } \\
\text { not assumed }\end{array}$ & 7.33 & .007 & 9.429 & 275 & .000 & 3.44 & .365 \\
\hline
\end{tabular}

\section{DISCUSSION}

The goal of this study has been to analyse exploratorily the possible differences in perceived stigma on drug use between a sample of students and health services workers from Italy and Belgium. Using the PSAS questionnaire it was found that the perceived stigma among Italians was statistically significantly higher $(M=23.68)$ than that reported by Belgians $(M=20.26)$. It is important to note that, despite having obtained statistically significant outcomes, the differences in means between the Italian and Belgian participants cannot be assumed as substantively significant due to the no-effect size of the differences analysed. No studies that have compared the perceived stigma related to drug users among samples from different countries. Therefore, it is not possible to compare this study's outcomes with previous evidence. In any case, there is evidence showing that drug use stigma in its various forms is a challenge drug users face when they are in their recovery process from their addiction (Fulton, 1999). 
In order to achieve a more comprehensive understanding of the problem of drug users stigmatization, researchers and mental health workers should be more sensitive not only to the cultural background that would partly explain the arising of stigmatizing attitude but also the influence of the social environment and the organization level. The main consequence of the stigmatising phenomena is that the person with drug dependence is entwined in a condition in which he or she is not able to escape from the situation and is simultaneously being defined by his or her association with a certain activity (i.e. drug use). In particular, as the authors' previous experience working at the Department for the Treatment and Prevention of Drug Abuse at Isernia showed, it is common to hear sentences referring to drug users as: "They are addicted; wasting themselves", "They are liars and dishonest", and "There is not a medical treatment to cure them". From this study's point of view, these sort of attitudes and prejudices act as significant obstacles to social and personal rehabilitation. Drug abusers often report fear of stigma as a barrier to seeking and/or entering treatment (Cunningham et al., 1993; Tucker, vuchinich, and Gladsjo, 1994). Therefore, perceived stigma would act as an important barrier to recovery from addiction (Luoma et al., 2010). In addition, social rejection also has its reflection on employment opportunities. There is less chance for drug users to get hired and to maintain their positions (MacDonald andPudney, 2000, 2001).

With the aim of explaining this issue, authors Scioli and Paniccia propose the existence of a circuit called stigma circuit which would share some similarities with the anxiety circuit since the person appears to be trapped in a vicious cycle of events (see figure 1) in both. 


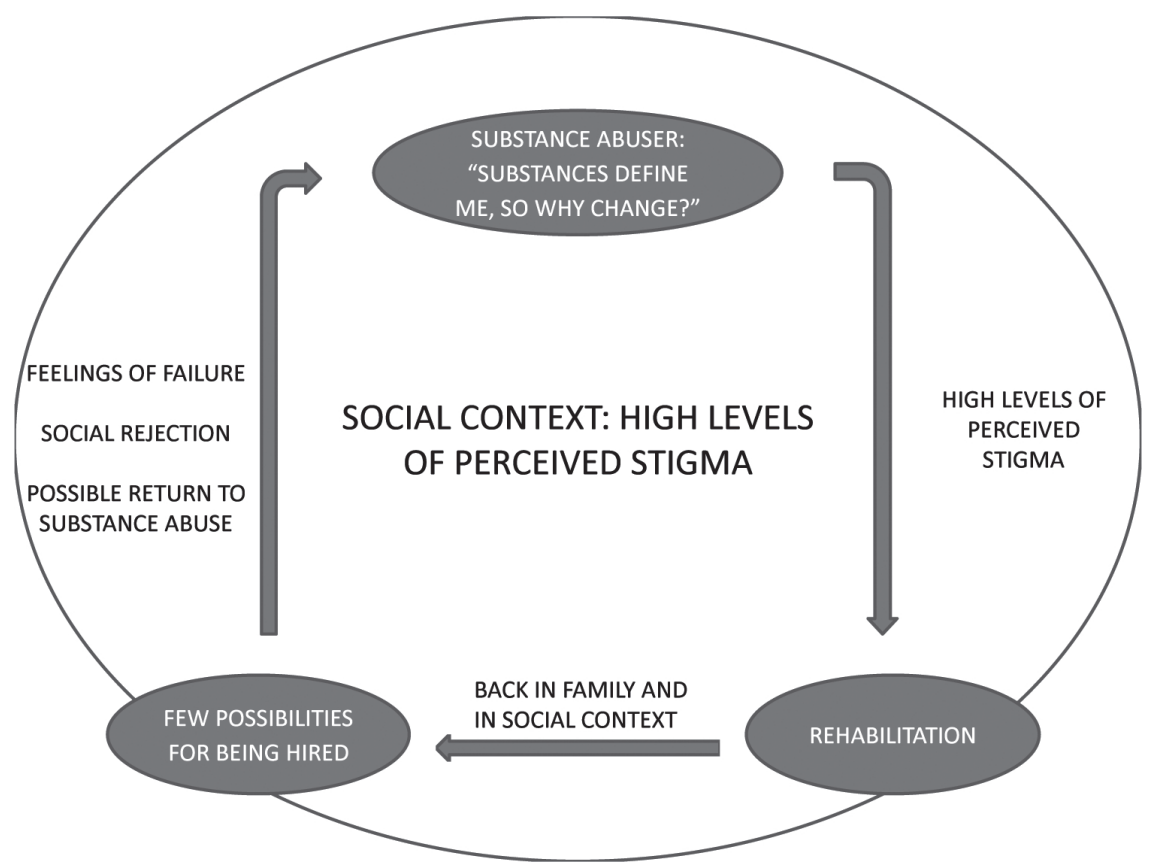

Figure 1. Stigma circuit of drug abusers.

The return of the person with an addiction to his or her original social context maintains the stigmatizing labels and attitudes of others that make rehabilitation from addiction harder.Therefore, the sense of failure and social rejection could lead the person with an addiction to a relapse into substance abuse. It is not contradictory that after a therapeutic intervention many people who have had problems related to their substance use tend to move away from the contexts in which they usually use drugs or even leave their countries of origin. The addict who remains, immersed back into a stigma-intensive environment, would be more inclined to use drugs, searching for sense and a definition of the self, based on the strong relationship that he or she shares with those in the peer group of users. This statement his even more significance for the addict who chooses substance as a definition of the self. The addict is in constant search of confirmation of his or her identity and uopn retunring to the original social context, he or she risks a relapse into substance abuse. This choice would also be led by a low level of mentalization and so the person would prefer substance to a possible rejection and to the feeling of failure that rise swith the high level of stigma that belonging to the context. An intervention in the cultural and social context -using strategies for prevention and treatment- would be aimed at diminishing the strength of this circle, which could be of great help for recovery in combination with psychotherapeutic interventions. 
The limitations of the study include the sample selection and the responses. A non-probabilistic convenience sampling was used to recruit the participants. Sociodemographic characteristics of the samples were not obtained. Therefore, it is unknown whether possible existing differences in sociodemographic characteristic could be influencing the obtained outcomes. In addition, the Italian sample $(n=200)$ was more numerous than the Belgian sample $(n=77)$. However, the scope of the present study is only exploratory. In this regard, the evidence obtained should only be taken with caution. Later controlled studies using larger samples and control measures for sociodemographic characteristics, religious affiliations, and cultural backgrounds will provide a greater understanding of the problems of stigmatizing attitudes on drug use.

\section{REFERENCES}

Ahern, J., Stuber, J., and Galea, S. (2007). Stigma, discrimination and the health of illicit drug users. Drug and Alcohol Dependence, 88, 188-196.

Brener, L., von Hippel, W., von Hippel, C., Resnick, I., and Treloar, C. (2010).

Perceptions of discriminatory treatment by staff as predictors of drug treat- ment completion: utility of a mixed methods approach. Drug and Alcohol Review, 29, 491-497.

Buchanan, J., and Young, L. (2000).The war on drugs-a war on drug users?Drugs; Education, Prevention and Policy, 7, 409-422.

Corrigan, P. W. (2000). Mental health stigma as social attribution: Implications for research methods and attitude change. Clinical Psychology: Science and Practice, 7, 48-67.

Corrigan, P. W., Kerr, A., and Knudsen, L. (2005). The stigma of mental illness: explanatory models and methods for change. Applied and Preventive Psychology, 11, 179-190.

Cunningham, J. A., Sobell, L. C., Sobell, M. B., Agrawal, S. and Toneatto, T. (1993). Barriers to treatment: why alcohol and drug abusers delay or never seek treatment. Addictive Behaviors, 18, 347-353.

Farina, A. (1998). Stigma.In K. T. Mueser and N. Tarrier (Eds.). Handbook of So- cial Functioning in Schizophrenia (pp. 247-279). Needham Heights, MA, United States: Allyn and Bacon.

Fulton, R. (1999). The stigma of substance use: A review of the literature. A report submitted to the committee on stigma and addiction at the Centre for Addiction and Mental Health.

Link, B. G., Yang, L. H., Phelan, J. C., and Collins, P. Y. (2004). Measuring mental illness stigma. Schizophrenia Bulletin, 30, 511-541.

Link, B. G., Cullen, F. T., Struening, E., Shrout, P. E., and Dohrenwend, B. P. (1989). A modified labeling theory approach to mental disorders: and empirical assessment. American Sociological Review, 54, 400-423.

Livingstone, J. D., Milne, T., Fang, M. L., and Amari, E. (2011). The effectiveness of interventions for reducing stigma related to substance use disorders: 
a sys- tematic review. Addiction, 107, 39-50.

Luoma, J. B., O'Hair, A. K. Kohlenberg, B. S., Hayes, S. C., and Fletcher, L. (2010). The development and psychometric proprieties of a new measure of perceived stigma towards substance users. Substance Use and Misuse, 45,4757.

Luoma, J. B., Twohig, M. P., Waltz, T., Hayes, S. C., Roget, N., Padilla, M., and Fisher, G. (2007). An investigation of stigma in individuals receiving treatment for substance abuse. Addictive Behaviors, 32, 1331-1346.

MacDonald, Z., and Pudney, S. (2000). Illicit drug use, unemployment, and occu- pational attainment. Journal of Health Economics, 19, 1089-1115.

MacDonald, Z., and Pudney, S. (2001). Illicit drug use and labour market achieve- ment: evidence from the UK. Applied Economics, 33, 1655-1668.

Metzner, R. (1994). Addiction and transcendence as altered states of consciousness. The Journal of Transpersonal Psychology, 26, 1-17.

Phelan, J. C., Link, B. G., Stueve, A., and Pescosolido, B. A. (2000). Public conceptions of mental illness in 1950 and 1996: What is mental illness and is it to be feared? Journal of Health and Social Behavior, 41, 188-207.

Rao, H., Mahadevappa, H., Pillay, P., Sessay, M., Abraham, A., and Luty, J. (2009). A study of stigmatized attitudes towards people with mental health problems among health proffesionals. Journal of Psychiatric and Mental Health Nursing, 16, 279-284.

Room, R. (2005). Stigma, social inequality and alcohol and drug use. Drug and Alcohol Review, 24, 143-155.

Rüsch, N., Angermeyer, M. C., and Corrigan, P. W. (2005). Mental illness stigma: Concepts, consequences, and initiatives to reduce stigma. European Psychiatry, 20, 529-539.

Schomerus, G., Laucht, M., Holzinger, A., Matschinger, H., Carta, M. G., and Angermeyer, M. C. (2011). The stigma of alcohol dependence compared with other mental disorders: a review of populations studies. Alcohol and Alcoholism, 46, 105-112.

Simmonds, L., and Coomber, R. (2009).Injecting drug users: a stigmatised and stigmatising population.International Journal of Drug Policy, 20, 121-130.

Tucker, J. A., Vuchinich, R. E., Galdsjo, J. A. (1994). Environmental events surrounding natural recovery from alcohol-related problems. Journal of Studies on Alcohol, 55, 401-411. 